\title{
The Implications of Cardiovascular Home Monitoring Rehabilitation - Mobile Applications as Optimum Solutions for the Future
}

\author{
http://dx.doi.org/10.3991/ijoe.v11i5.4864 \\ M. Răileanu, S. Busnatu and C. Sinescu \\ University of Medicine and Pharmacy „Carol-Davila”, Bucharest, Romania
}

\begin{abstract}
This paper examines the home monitoring system used in our Department of Cardiology in the Future Internet Social Technological Alignment in Healthcare (FISTAR) project - a project focused on secondary prevention in cardiology (www.fi-star.eu). The system used is composed of bluetooth capable medical devices that collect vital parameters though CardioStar application (an application that was developed in collaboration with computer engineers. The collected data are transmitted in real time to a central server in our hospital, where there is a continuous supervision of the parameters. We evaluated this system in order to prove its use in reducing the cardiovascular risk and increasing the adherence to the life-style changes.
\end{abstract}

This paper presents the analysis of the MAST (Model for Assessment of Telemedicine) evaluation - which is the best way of evaluation for the telemedicine solutions - from the professional point of view. The questionnaires of evaluation were performed anonymous on a online platform. The application passed successfully the MAST evaluation, demonstrating that the developed telemedicine system designed for our cardiac patients fulfills its purpose in the secondary prevention.

Index Terms - electronic devices, home monitoring system, mobile application, telemedicine.

\section{BACKGROUND}

Telemedicine is a new and provocative area for the modern medicine, offering new perspectives especially in the prevention field. The home monitoring systems were proved to be a motivational factor for the primary prevention to the persons who have risk factors to develop a cardiovascular disease and, of course an important motivational factor for the secondary prevention for those who already suffer of a cardiac disease and who want to prevent its complications, or to rehabilitate after an acute cardiovascular event.

The development of technology in medicine field has brought a new frontier with interdisciplinary perspectives of exploration, being a borderline issue between medicine, informatics and socio-ethics. Concerns over the privacy of the health information systems and the health communications devices are new and debated in the telemedicine field, because the telemedicine area is itself a new domain.

\section{INTRODUCTION}

Our Department of Cardiology from the Emergency Hospital "Bagdasar-Arseni" within the University of
Medicine and Pharmacy "Carol-Davila", Bucharest, started a vast FP7 project at the beginning of the 2013, through we tested a telemedicine solution for the home rehabilitation of the patients who suffered an acute cardiovascular event. This study developed in our Clinic is part of the "Future and Technological Alignment Research (FI-STAR)".

There are different countries in the Europe who are testing this telemedicine solution in different fields of medicine, but our country, respectively our Department of Cardiology was responsible of the cardiovascular diseases.

So we developed a mobile application - CardioStar that was designed for the Romanian speaking people and which is able to recognize the electronic devices that we offer to each patient for home monitoring of the vital parameters and to record them, and of course to transmit them to our central server from the hospital in real time (Fig. 1). This central server is supervised by a medical doctor all the time, so any medical problem can be approached in time (Fig. 2).

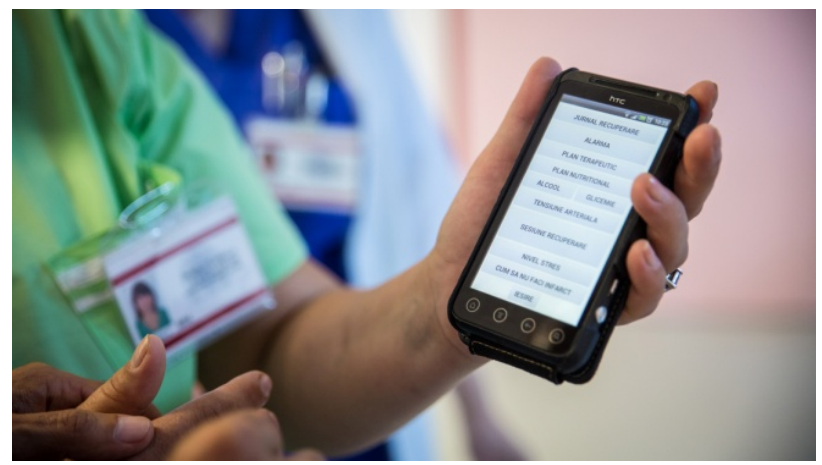

Figure 1. CardioStar Mobile Device

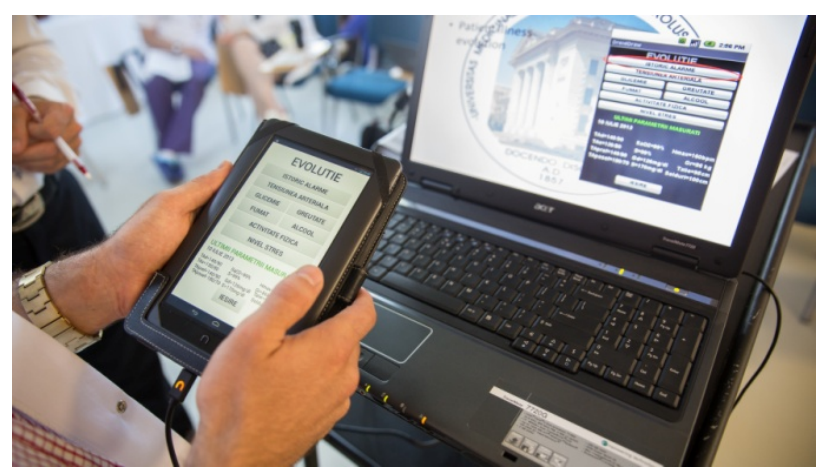

Figure 2. The Central Server 
Monitoring the patients with cardiovascular diseases is an important point of the secondary prevention after their discharge from the hospital. The problem is that many patients don't come to the hospital for reevaluation until they are in a really bad condition of their health. The home-monitoring systems are the optimal solution for all the cardiovascular patients in order to reduce their cardiovascular risk on a long term, to prevent major cardiac events after discharge from the hospital, to reduce the costs of hospitalization and to increase the adherence of the patient to the therapy.

\section{Material AND Methods}

Since January 2015 we included in our study 50 persons with cardiovascular diseases who were supervised via mobile devices and telemonitoring systems during their long term recuperation program while they were at home.

After their discharge from the hospital, each one of them received a specific recuperation plan that consisted in specific lifestyle changes, diet, physical activity and medication, and this plan was supervised by our medical staff through the CardioStar application (Fig. 3).

The socio-ethical problems were taken into account from the very beginning. In this regard we started the application only after the accomplishing the socio-ethical aspects like the signing of the Informed Consent, the testing of the security of the mobile application, the ensuring of the protection of the transmitted data and of the recorded data on the mobile application and on the central server.

The security of the private information was tested by our study equip formed by programmers and doctors who took into account all the safety measures before the application to be distributed to the patients.

First of all, this safety test consisted in assuring the protection of the database (on the central server in our hospital) by encrypting it with user and password. Only the supervisory staff had full access to the database.

Then the application on the mobile phone was protected also by different user and password for each one of the patients. Also for safety reasons, after each use of the application, this was totally removed from the device and reinstalled for the next user.

After all these precautions, was performed a test for the application with anonymous data obtained from the professional stuff that coordinated our study. We mention that the professional stuff included 10 persons who are as profession medical doctors or engineers in computers.

In addition to the objective evaluation of the security of the data that included the denying of the access from any other electronic device or communication media, we evaluated this application from the ethic point of view, by a specific socio-ethic questionnaire that included the security evaluation.

We also evaluated the application regarding the quality of the parameters and fulfillment of its objectives from the view of the patient and of the professional team.

This evaluation was done using a personalized MAST (Model for Assessment of Telemedical Solution) e-Health impact evaluation questionnaire that was completed after six months of evaluation of our telemedical solution.

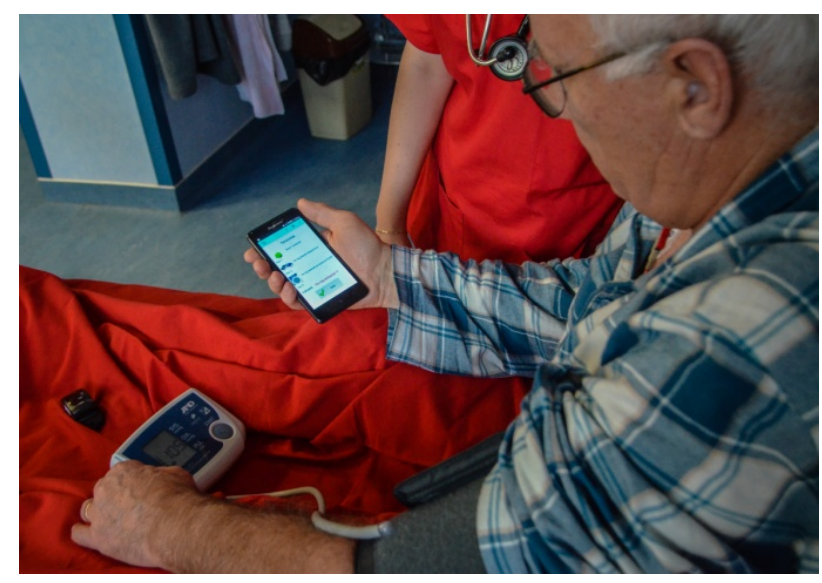

Figure 3. Patient using CardioStar application

We asked the professional stuff to complete these two questionnaires after they had enough experience (six months of experience with their patients who used the application).

The results presented below are the ones who were addressed to the professional stuff, responsible for the organization and coordination of this research.

FI-STAR MAST (Model for Assessment of Telemedicine) Questionnaire for Professionals

1. How satisfied are you with the application's health care output in its entirety?

○ Very well; well; neutral; poorly; very poorly.

2. How well the application fulfills your expectations in health care delivery?

○ Very well; well; neutral; poorly; very poorly.

3. Imagine a perfect application in all aspects of health care delivery. How far away from that is the application you are using today?

- Very close; somehow close; neutral; far; very far.

4. Accessibility:The application is easily accessible for different groups of users.

○ 5-point Likert-scale: Strongly agree strongly disagree. 6: not applicable.

5. Adhereability: The application helps patients to more adherence by some sort of motivators (i.e. being a member of a community.

○ 5-point Likert-scale: Strongly agree strongly disagree. 6: not applicable.

6. Affordability: The health care service delivered through the application is more affordable or decrease expenditures, comparing with other alternatives.

○ 5-point Likert-scale: Strongly agree strongly disagree. 6: not applicable.

7. Availability: The service which is provided by the application, is available on demand.

○ 5-point Likert-scale: Strongly agree strongly disagree. 6: not applicable.

8. Efficiency: The application has increased efficiency by reducing: complexity or number of tasks, number of reworks, time consumed. 
- 5-point Likert-scale: Strongly agree strongly disagree. 6: not applicable.

9. Effectiveness: The application has increased effectiveness, especially by improving at least one of these items:

- less mistakes:

- 5-point Likert-scale: Strongly agree - strongly disagree. 6: not applicable.

- readiness or promptness for different situations:

- 5-point Likert-scale: Strongly agree - strongly disagree. 6: not applicable.

- more knowledge and evidences:

○ 5-point Likert-scale: Strongly agree - strongly disagree. 6: not applicable.

- more personalized treatment:

○ 5-point Likert-scale: Strongly agree strongly disagree. 6: not applicable.

10. Empowerment: The application empowers the patient by increasing their knowledge about their situation or general knowledge about the disease.

○ 5-point Likert-scale: Strongly agree strongly disagree. 6: not applicable.

The application empowers the medical personnel by increasing their knowledge about the patient situation or general knowledge about the disease.

\section{○ 5-point Likert-scale: Strongly agree -} strongly disagree. 6: not applicable.

11. Safety: It is safe for the patients to use the application without any possibility of disability, morbidity, or mortality harm.

○ 5-point Likert-scale: Strongly agree strongly disagree. 6: not applicable.

It is safe for the medical personnel to use the application without any possibility of disability, morbidity, or mortality harm.

○ 5-point Likert-scale: Strongly agree strongly disagree. 6: not applicable.

The application provides correct information without any mislead or confusion.

○ 5-point Likert-scale: Strongly agree strongly disagree. 6: not applicable.

The application provides enough information on how to minimize possible harms during the usage.

○ 5-point Likert-scale: Strongly agree strongly disagree. 6: not applicable.

If the application fails, and if the failure causes any harm, then the harm would be minor as it would be non-severe, rarely happening, or happening for a very short duration.

○ 5-point Likert-scale: Strongly agree strongly disagree. 6: not applicable.
The application improves health care safety by detecting emergency situations, unsafe behaviors or glitches in the process.)

○ 5-point Likert-scale: Strongly agree strongly disagree. 6: not applicable.

12. Trustability: The application attains trust of patients (for example by ensuring privacy of their information or being non-invasive in its interaction with them).

○ 5-point Likert-scale: Strongly agree strongly disagree. 6: not applicable.

\section{A. FI-STAR Socio-ethical Questionnaire for Professionals}

User Involvement / responsiveness

- The application allows for providing feedback to its developers in order to increase the fit between current and expected functions.

○ 5-point Likert-scale: Strongly agree strongly disagree.

User Exclusion

- The application needs (technically) skilled users in order to make good use of the application.

○ 5-point Likert-scale: Strongly agree strongly disagree.

Professional-Patient Relationship / autonomy

- The use of the application increased my ability to make choices that fit good healthcare delivery.

- 5-point Likert-scale: Strongly agree strongly disagree. 6: not applicable

Social Environment Impact

- The use of the application has positively changed the social status of certain conditions (e.g. conceptions of people with a particular disease).

Organizational Impact.

5-point Likert-scale: Strongly agree strongly disagree. 6: not applicable.

- The application has positively changed the way I organize my work.

- 5-point Likert-scale: Strongly agree strongly disagree. 6: not applicable.

All the factors revealed by these two questionnaires were grouped in 5 parameters for the statistical analysis depending on its characteristics:

Parameter 1: user feedback and sentiment analysis (which reveals the following characteristics: expectance, accessibility, adherence, affordability, social environment, impact, interface).

Parameter 2: crash analysis (which reveals the following characteristics: app`s output, organizational impact, devices`output)

Parameter 3: in-app bug reporting (which reveals the following characteristics: effectiveness, user involvement, responsiveness, errors, user exclusion) 
Parameter 4: over-the-air app build distribution (which reveals the following characteristics: availability, safety, trustworthiness, confidence).

Parameter 5: evidence-based prioritization (which reveals the following characteristics: efficiency, empowerment, relation with professionals, autonomy).

\section{RESUlts}

The score value is standardized for each one of the parameters. The Satisfactory Score depend on the parameter and it is described in the Table II, under each one of the parameters, as well as the Unsatisfactory Score. We obtained a Satisfactory Score from the professional questionnaires for all the parameters with a statistical significance. Except the first parameter where p-value cannot be evaluate (because the number of the questionnaires with unsatisfactory score was only one in this case), for the rest of parameters we obtained a significant $p$-value $(<0,05)$ as follows:

-parameter 2: p-value $=0,000183$ (Table II, Table III) -parameter 3: p-value $=0,032$ (Table II, Table IV) -parameter 4: p-value $=0,0003$ (Table II, Table V) -parameter 5: p-value $=0,0004$ (Table II, Table VI)

TABLE I.

DESCRIPTIVE ANALYSIS IN THE PROFESSIONAL GROUP

\begin{tabular}{|c|c|}
\hline Characteristics in the proffesionals` group & Statistics \\
\hline Age, $y r$ (median, range) - Graph 1 & $31(27-63)$ \\
\hline Male, $\mathrm{n}(\%)$ & $2 / 10(20 \%)$ \\
\hline Female, $\mathrm{n}(\%)$ & $8 / 10(80 \%)$ \\
\hline
\end{tabular}

TABLE II.

SUMMARY OF THE RESULTS

\begin{tabular}{|c|c|c|c|}
\hline & $\begin{array}{l}\text { Characteristics in the } \\
\text { proffesionals' group }\end{array}$ & Statistics & p-value \\
\hline Parameter 1 & Score (median; range) & $8 ; 7-17$ & \multirow[t]{3}{*}{ NA* } \\
\hline $\begin{array}{l}\text { Satisfactory Score } \\
\text { (standard 7-14) }\end{array}$ & median; range; percent & $\begin{array}{c}8 ; 7-12 \\
90 \%\end{array}$ & \\
\hline $\begin{array}{l}\text { Unsatisfactory Score } \\
\text { (standard 15-35) }\end{array}$ & median; range; percent & $\begin{array}{c}17 ; \mathrm{NA}^{*} \\
(90 \%)\end{array}$ & \\
\hline Parameter 2 (Table III) & Score (median; range) & $3 ; 3-10$ & \\
\hline $\begin{array}{l}\text { Satisfactory Score } \\
\text { (standard 3-8) }\end{array}$ & median; range; percent & $\begin{array}{c}3 ; 3-6 \\
80 \%\end{array}$ & 0,000183 \\
\hline $\begin{array}{l}\text { Unsatisfactory Score } \\
\text { (standard 9-15) }\end{array}$ & median; range; percent & $\begin{array}{c}9,5 ; 9-10 \\
20 \%\end{array}$ & \\
\hline \begin{tabular}{|l|} 
Parameter 3 (Table IV) \\
\end{tabular} & Score (median; range) & 5,$5 ; 5-13$ & \\
\hline $\begin{array}{c}\text { Satisfactory Score } \\
\text { (standard 5-10) }\end{array}$ & median; range; percent & $\begin{array}{c}5 ; 5-9 \\
80 \% \\
\end{array}$ & 0,032 \\
\hline $\begin{array}{l}\text { Unsatisfactory Score } \\
\text { (standard 11-25) }\end{array}$ & median; range; percent & $\begin{array}{c}12 ; 11-13 \\
20 \%\end{array}$ & \\
\hline \begin{tabular}{|l|} 
Parameter 4 (Table V) \\
\end{tabular} & Score (median; range) & 5,$5 ; 4-10$ & \\
\hline $\begin{array}{l}\text { Satisfactory Score } \\
\text { (standard 4-8) }\end{array}$ & median; range; percent & $\begin{array}{c}4 ; 4-8 \\
70 \%\end{array}$ & 0,0003 \\
\hline $\begin{array}{l}\text { Unsatisfactory Score } \\
\text { (standard 9-20) }\end{array}$ & median; range; percent & $\begin{array}{c}9 ; 9-10 \\
30 \% \\
\end{array}$ & \\
\hline \begin{tabular}{|l|} 
Parameter 5 (Table VI) \\
\end{tabular} & Score (median; range) & 6,$3 ; 4-9$ & \\
\hline $\begin{array}{l}\text { Satisfactory Score } \\
\text { (standard 4-8) }\end{array}$ & median; range; percent & $\begin{array}{c}5 ; 4-8 \\
70 \%\end{array}$ & 0,0004 \\
\hline $\begin{array}{l}\text { Unsatisfactory } \\
\text { Score (standard 9- } \\
20 \text { ) }\end{array}$ & $\begin{array}{l}\text { median; range; } \\
\text { percent }\end{array}$ & $\begin{array}{c}9 ; 9-9 ; \\
30 \%\end{array}$ & \\
\hline
\end{tabular}

TABLE III.

PARAMETER 2 - STATISTICAL SEMNIFICATION

\begin{tabular}{|c|r|r|}
\hline \multicolumn{3}{|c|}{ T-Test: Two-Sample Assuming Equal Variances } \\
\hline & Variable 1 & Variable 2 \\
\hline Mean & 3,625 & 9,5 \\
\hline Variance & 1,410714 & 0,5 \\
\hline Observations & 8 & 2 \\
\hline Pooled Variance & 1,296875 & \\
\hline Hypothesized Mean Difference & 0 & \\
\hline $\mathrm{df}$ & 8 & \\
\hline $\mathrm{t}$ Stat & $-6,52558$ & \\
\hline $\mathrm{P}(\mathrm{T}<=\mathrm{t})$ one-tail & $9,16 \mathrm{E}-05$ & \\
\hline $\mathrm{t}$ Critical one-tail & 1,859548 & \\
\hline $\mathbf{P}(\mathbf{T}<=\mathbf{t})$ two-tail & $\mathbf{0 , 0 0 0 1 8 3}$ & \\
\hline $\mathrm{t}$ Critical two-tail & 2,306004 & \\
\hline
\end{tabular}

TABLE IV.

PARAMETER 3 - STATISTICAL SEMNIFICATION

T-Test: Two-Sample Assuming Unequal Variances

\begin{tabular}{|c|r|r|}
\hline \multicolumn{4}{|c|}{ T-Test: Two-Sample Assuming Unequal Variances } \\
\hline & Variable 1 & Variable 2 \\
\hline Mean & 5,875 & 12 \\
\hline Variance & 2,125 & 2 \\
\hline Observations & 8 & 2 \\
\hline Hypothesized Mean Difference & 0 & \\
\hline $\mathrm{df}$ & 2 & \\
\hline $\mathrm{t}$ Stat & $-5,44444$ & \\
\hline $\mathrm{P}(\mathrm{T}<=\mathrm{t})$ one-tail & 0,01606 & \\
\hline $\mathrm{t}$ Critical one-tail & 2,919986 & \\
\hline $\mathbf{P}(\mathbf{T}<=\mathbf{t})$ two-tail & $\mathbf{0 , 0 3 2 1 1 9}$ & \\
\hline $\mathrm{t}$ Critical two-tail & 4,302653 & \\
\hline
\end{tabular}

TABLE V.

PARAMETER 4 - STATISTICAL SEMNIFICATION

\begin{tabular}{|c|r|r|}
\hline \multicolumn{3}{|c|}{ T-Test: Two-Sample Assuming Unequal Variances } \\
\hline & \multicolumn{1}{|l|}{ Variable 1 } & Variable 2 \\
\hline Mean & 5 & 9,333333 \\
\hline Variance & 3 & 0,333333 \\
\hline Observations & 7 & 3 \\
\hline Hypothesized Mean Difference & 0 & \\
\hline df & 8 & \\
\hline t Stat & $-5,89865$ & \\
\hline P(T<=t) one-tail & 0,000181 & \\
\hline t Critical one-tail & 1,859548 & \\
\hline P(T<=t) two-tail & $\mathbf{0 , 0 0 0 3 6 2}$ & \\
\hline t Critical two-tail & 2,306004 & \\
\hline
\end{tabular}

TABLE VI

PARAMETER 5 - Statistical Semnification

\begin{tabular}{|c|r|r|}
\hline \multicolumn{3}{|c|}{ T-Test: Two-Sample Assuming Unequal Variances } \\
\hline & Variable 1 & Variable 2 \\
\hline Mean & 5,142857 & 9 \\
\hline Variance & 2,142857 & 0 \\
\hline Observations & 7 & 3 \\
\hline Hypothesized Mean Difference & 0 & \\
\hline $\mathrm{df}$ & 6 & \\
\hline $\mathrm{t}$ Stat & $-6,97137$ & \\
\hline $\mathrm{P}(\mathrm{T}<=\mathrm{t})$ one-tail & 0,000217 & \\
\hline $\mathrm{t}$ Critical one-tail & 1,94318 & \\
\hline $\mathbf{P}(\mathbf{T}<=\mathrm{t})$ two-tail & $\mathbf{0 , 0 0 0 4 3 3}$ & \\
\hline $\mathrm{t}$ Critical two-tail & 2,446912 & \\
\hline & & \\
\hline
\end{tabular}




\section{DISCUSSION}

It is obviously that our propose regarding a specific mobile application for the secondary prevention in cardiovascular diseases was well rated by our professional supervisor group, because of its important contribution to the their work improvement, to a better relationship with the patient, to a better supervision of the patient's cardiac evolution and health condition, and of course in terms of a better organization of their time. More than these we obtained a well rated socio-ethical impact in terms of security and privacy of the medical information, and we understood that this is an optimal solution for ensuring to our patients a proper and a safe medium of their medical data transmission.

Because we tested this application only in our Department of Cardiology which is the first Department in our country which tests an application which monitor the vital cardiovascular parameters at home, we had only a small professional equip who managed to supervise the 50 patients that we tested during these 6 months.

But we hope that our project will be soon extended to more centers in our country, and that our application will be soon used by more doctors, so we expect to have as soon as possible a new evaluation to a large scale.

\section{CONCLUSION}

Mobile applications and afferent devices are for sure the future of medicine, especially in the prevention sector (even if we talk about primary or secondary prevention. As we remarked in our study, the use of these monitoring devices involves a lot of medical, social, ethical implications. We tested their statistical signification by the qualitative tests, and by the periodical technical evaluation of the devices (that were done both by doctors and by computer engineers). We obtained satisfactory result, with statistical signification, regarding the positive impact of the using of these devices by our patients.

In conclusion, we expect soon a "revolution" of our medical system in our country that will save our time, our money invested in the medical system, and of course, that will save the lives of our patients who will be well monitored and approached in time when the medical parameters are changed in the wrong direction.

\section{REFERENCES}

[1] ACP (1998). "Ethics Manual: Fourth Edition.” Annals of Internal Medicine 128(7): 577- 594.

[2] Agich, G. J. (1993). Autonomy and Long-Term Care. New York, Oxford University Press.

[3] Allen, A. (1995). Privacy in Healthcare. Encyclopedia of Bioethics. New York, Simon \& Schuster Macmillan: 2064-2073.

[4] Almagro UA, Dunn BE, Choi H, Recla DL, Weinstein RS. The gross pathology workstation: An essential component of a dynamic-robotic telepathology system. Cell Vision 1996; 3:470-473.

[5] Allen, A. (2000). "Morphing Telemedicine, Telecare, Telehealth, eHealth." Telemedicine Today 2000 Buyer's Guide and Directory: 1, 43. AMA (1996). Report 9 of the Council on Scientific Affairs (I-96): On Site Physician Home Health Care. Chicago, AMA Press. AMA (2000). Code of Medical Ethics: Current Opinions with Annotations. Chicago, AMA Press.

[6] Atoui H, Fayn J, Rubel P. A neural network approach for patientspecific 12-lead ECG synthesis in patient monitoring environments. Comput Cardiol 2004;31:161
[7] Beasly, A. and G. Graber (1984). "The Range of Autonomy: Informed Consent in Medicine." Theoretical Medicine 5: 31-41. Beauchamp, T. and J. Childress (1994). Principles of Biomedical Ethics. New York, Oxford University Press.

[8] Belas, E. A., F. Jaffrey, et al. (1997). "Electronic Communications with Patients: Evaluation of Distance Medicine Technology." Journal of the American Medical Association 278(2): 152-159. Benn, S. and G. Gaus (1983). The Private and the Public in Social Policy. London, Croon Helm and St. Martin Press.

[9] Carmen Ginghina, Mic tratat de cardiologie, Ed. Academiei Române, 2010;265-284.

[10] Council of Europe (1999). Guidelines for the Protection of Individuals with Regard to the Collection and Processing of Personal Data on Information Highways. Strasbourg.

[11] Dan L. Longo, Anthony S. Fauci, Dennis L. Kasper, Stephen L. Hauser,, J. Larry Jameson, Joseph Loscalzo, Harrison`s Principles of Internal Medicine

[12] Darkins, A. (1996). "The Management of Clinical Risks in Telemedicine Applications." Journal of Telemedicine and Telecare 2: 179-184. http://dx.doi.org/10.1258/1357633961930022

[13] Douglas L. Mann, Douglas P. Zipes, Peter Libby, Braunwald's Heart Desease

[14] Evaluating the Benefits: Newfoundland and Labrador Provincial Telehealth Program, Chronic Disease Management. 2010. Available

http://www.nlchi.nl.ca/images/PDFs/Evaluating\%20the\%20Benefi ts $\% 20-\quad \% 20 \mathrm{NL} \% 20$ Provincial $\% 20$ Telehealth\%20Program $\% 20$ \%20Chronic\%20Disease\%20Mgmt.pdf

[15] Murphy G, Prichett-Pejic W, Severn M. Non-Emergency Telecardiology Services: A Rapid Review of Clinical and Cost Outcomes. 2010;134. Available at: http://www.cadth.ca/media/pdf /H0501 Telecardiology Report e.pdf

[16] Pak H, Triplett CA, Lindquist JH, Grambow SC, Whited JD. Store-and-forward teledermatology results in similar clinical outcomes to conventional clinic-based care. J Telemed Telecare 2007;13(1):26-30. http://dx.doi.org/10.1258/1357633077797 $\underline{01185}$

[17] Roth A et al. Potential Reduction of Costs and Hospital Emergency Department Visits resulting from Prehospital Transtelephonic Triage - The Shared Experience in Israel. Clinical Cardiology 2000; 23: 271-276. http://dx.doi.org/10.1002/clc.4960230410

[18] Rubel P, Fayn J, et al. New paradigms in telemedicine: ambient intelligence, wearable, pervasive and personalized. Stud Health Technol Inform 2004;108:123.

[19] http://ec.europa.eu/justice/data-protection/

[20] https://www.fi-star.eu/use-cases.html

[21] http://www.healthcourse.com/our-e-learning-platform/

[22] http://legislatie.resurse-pentru-democratie.org/legea/6772001.php

[23] http://www.research.ro/ro/articol/1021/despre-ancs-legislatie

\section{AUTHORS}

M. Răileanu is M.D. within University of Medicine and Pharmacy „Carol-Davila”, Bucharest (e-mail: ella_rln@yahoo.com).

Ş.Busnatu is M.D. within University of Medicine and Pharmacy „Carol-Davila”, Bucharest (e-mail: busnatustefan@yahoo.com).

C.Sinescu is Prof. M.D., head of the Cardiology Department of the Emergency Hospital „BagdasarArseni", Bucharest, within University of Medicine and Pharmacy „Carol-Davila”, Bucharest (e-mail: crinasinescu@gmail.com).

The work presented has received funding from the European Union's Seventh Program for research, Technological development and demonstration under grant agreement No 604691 - FI-STAR PROJECT and from UEFISCDI Romania. Submitted 15 July 2015. Published as resubmitted by the authors 20 August 2015. 